\title{
Divergência genética entre acessos de espinheira-santa (Maytenus ilicifolia Mart. ex Reissek e M. aquifolium Mart.) com base em caracteres morfológicos e fisiológicos
}

\author{
MARIOT, M.P. ${ }^{1 *}$; BARBIERI, R.L. ${ }^{2}$ \\ ${ }^{1}$ Universidade Federal de Pelotas, Avenida Ildefonso Simões Lopes, 2791, CEP: 96.060-290, Pelotas-Brasil \\ *marciomariot@gmail.com ${ }^{*}$ Embrapa Clima Temperado, BR 392, km 78, Caixa Postal 403, CEP: 96.001-970, \\ Pelotas-Brasil
}

\begin{abstract}
RESUMO: Maytenus ilicifolia e M. aquifolium (espinheira-santa) são espécies medicinais nativas do Brasil ameaçadas de extinção devido à forte ação antrópica nas populações naturais. $O$ objetivo deste trabalho foi avaliar a divergência genética em germoplasma de espinheira-santa, e agrupar os acessos através de análises multivariadas, com base em caracteres morfo-fisiológicos das progênies. Foram avaliados 89 acessos do banco ativo de germoplasma de espinheira-santa da Embrapa Clima Temperado/Universidade Federal de Pelotas. Os caracteres avaliados foram dias da semeadura à emergência; altura e diâmetro à base do caule, aos 90, 180, 270 e 360 dias; crescimento em altura e diâmetro à base do caule; comprimento e largura de folha e número de espinhos por folha. O delineamento experimental foi em blocos casualizados, com quatro repetições e cinco plantas por parcela. Os dados foram submetidos à análise de variância e análise de variância multivariada, sendo estimadas as variáveis canônicas. Os caracteres avaliados foram eficientes para separar os acessos em três grupos. As variáveis altura, diâmetro à base do caule aos 360 dias e número de folhas aos 180 dias são as mais importantes para caracterização do germoplasma de espinheira-santa.
\end{abstract}

Palavras-chave: Maytenus ilicifolia, Maytenus aquifolium, germoplasma, análise multivariada

\begin{abstract}
Genetic divergence among "espinheira-santa" (Maytenus ilicifolia Mart. ex Reiss. and $M$. aquifolium Mart.) accessions based on morphological and physiological traits. Maytenus ilicifolia and M. aquifolium ("espinheira-santa") are medicinal species native to Brazil. They are endangered due to the strong anthropic action in natural populations. The aim of this work was to evaluate the genetic divergence in "espinheira-santa" germplasm and to cluster accessions by multivariate analyses based on morphophysiological traits of progenies. Eightynine accessions of the "espinheira-santa" active germplasm bank from the Brazilian Agricultural Research Corporation (EMBRAPA) Temperate Agriculture, Pelotas Federal University, Pelotas Municipality, Rio Grande do Sul State, Brazil, were evaluated regarding days from sowing to emergence; height and stem-base diameter at 90, 180, 270 and 360 days; height and stem-base diameter growth; leaf length and width; and number of thorns per leaf. Experimental design was in randomized blocks, with four replicates and five plants per plot. The results were subjected to analysis of variance and multivariate analysis of variance, and canonical variables were estimated. The evaluated traits were efficient for separating the accessions into three clusters. Height and stem-basal diameter at 360 days and leaf number at 180 days were the most important for "espinheira-santa" germplasm characterization.
\end{abstract}

Key words: Maytenus ilicifolia, Maytenus aquifolium, germplasm, multivariate analysis

\section{INTRODUÇÃO}

Maytenus ilicifolia e M. aquifolium, pertencentes à família Celastraceae e popularmente conhecidas como espinheira-santa, são espécies nativas do Brasil que apresentam alto valor medicinal no tratamento de gastrite e úlcera gástrica (Di Stasi, 2004). Maytenus é um gênero predominantemente americano, caracterizado pelo hábito arbustivo ou arbóreo. As características que diferenciam as duas

Recebido para publicação em 22/04/2008

Aceito para publicação em 11/03/2010

Rev. Bras. PI. Med., Botucatu, v.12, n.3, p.243-249, 2010. 
espécies de espinheira-santa são a presença de ramos jovens tetra ou multicarenados, angulosos em $M$. ilicifolia, enquanto que em $M$. aquifolium os ramos são arredondados ou achatados, lisos. Além disso, a disposição das folhas nos ramos em $M$. ilicifolia é de forma helicoidal e em $M$. aquifolium é paralela (Carvalho-Okano, 1992; Carvalho-Okano \& Leitão Filho, 2004).

Devido à perda na variabilidade genética de espinheira-santa nas populações naturais, esta espécie é considerada prioritária para conservação (Vieira, 1999). Com o propósito de conservar a variabilidade genética destas espécies, a Embrapa Clima Temperado e a Universidade Federal de Pelotas implantaram banco ativo de germoplasma (BAG) de M. ilicifolia e M. aquifolium, em que acessos oriundos de diferentes locais foram coletados, caracterizados morfologicamente e conservados (Mariot, 2005). Através dos dados de caracterização dos acessos é possível realizar análises multivariadas, as quais permitirão que seja estimada a divergência genética entre os acessos do banco de germoplasma. Este estudo possibilita que se conheça melhor o germoplasma disponível, facilitando o trabalho de conservação, pois é possível descartar acessos que sejam muito próximos geneticamente, reduzindo o tamanho do BAG, além de possibilitar escolher os caracteres mais importantes para serem utilizados na caracterização de acessos.

Em espinheira-santa, estudos da divergência genética foram realizados através de marcadores moleculares do tipo RAPD (Bittencourt, 2000; Mossi, 2003), isoenzimas (Scheffer, 2001; Perecin \& Kageyama, 2002; Steenbock, 2003) e metabólitos secundários (Mossi, 2003). Em todos os trabalhos foi identificada maior variabilidade dentro de populações do que entre populações, o que é esperado para espécies de fecundação cruzada. Este mesmo resultado foi observado por Mariot et al. (2008) através de análise multivariada realizada com base nos caracteres morfológicos avaliados nas matrizes de espinheira-santa, que deram origem as progênies que compõem o BAG da Embrapa Clima Temperado/ Universidade Federal de Pelotas.

Foi destacado por Perecin et al. (2004) que, apesar da grande riqueza alélica encontrada em $M$. ilicifolia e $M$. aquifolium, através de análise de isoenzimas, o número de alelos com baixa frequência é muito alto, o que deve ser motivo de preocupação. Segundo os autores, estas espécies possuem muitos alelos que podem ser classificados como raros, os quais são mais facilmente perdidos quando comparados aos alelos mais comuns.

A caracterização de acessos em banco de germoplasma sempre inicia pela caracterização morfológica, o que é fundamental para o maior conhecimento do germoplasma que se está trabalhando com vistas a conservação. Neste sentido, este trabalho foi realizado com o objetivo de estudar a divergência genética entre acessos de espinheirasanta e agrupá-los através de análises multivariadas, por meio de dados de caracteres morfo-fisiológicos avaliados nas progênies na fase de muda.

\section{MATERIAL E MÉTODO}

Foram avaliadas as progênies de irmãos maternos de 89 acessos de espinheira-santa oriundos de matrizes de populações localizadas no Estado do Rio Grande do Sul. As sementes destas matrizes, coletadas no campo ou em quintais, foram utilizadas para produção das progênies que compõem o banco de germoplasma da Embrapa Clima Temperado/ Universidade Federal de Pelotas. A relação dos acessos e os respectivos locais de origem encontram-se na Tabela 1. Cada acesso corresponde a uma matriz que originou um grupo de progênies de meios-irmãos.

A maioria dos acessos coletados pertence à espécie $M$. ilicifolia e foram coletados apenas quatro acessos de $M$. aquifolium. Esta espécie é mais rara do que a outra, o que justifica a coleta e conservação, além do fato de ambas compartilharem alelos, segundo Perecin \& Kageama (2002).

As populações onde foram feitas as coletas apresentam poucos indivíduos, principalmente devido às roçadas (Mariot, 2005). A maioria das plantas é arbustiva e encontra-se em campo, com topografia plana, em locais meio-sombreado ou ensolarado. A variação total da altura das plantas matrizes é de $0,42 \mathrm{~m}$ a 6,0 $\mathrm{m}$ para M. ilicifolia e de $2,50 \mathrm{~m}$ a $8,50 \mathrm{~m}$ para $M$. aquifolium. Com relação ao diâmetro à base do caule, a variação total para $M$. ilicifolia é de 0,50 $\mathrm{cm}$ a $12,0 \mathrm{~cm}$, enquanto que para $M$. aquifolium é de $5,50 \mathrm{~cm}$ a $35,0 \mathrm{~cm}$. A época de maturação dos frutos varia de acordo com a latitude, iniciando em novembro na Metade Sul e terminando em janeiro na Região Nordeste do Estado. Apesar de apresentar uma ampla distribuição no Rio Grande do Sul, a espinheira-santa é mais escassa na Região Nordeste do Estado.

Sementes coletadas entre os meses de outubro de 2002 e janeiro de 2003, quando os frutos se encontravam em estádio de maturação, foram semeadas em fevereiro de 2003 em sacos de polietileno preto, com dimensões de $10 \times 17 \mathrm{~cm}$, em telado, na Embrapa Clima Temperado. O substrato utilizado constou de areia média, esterco bovino curtido e terra, na proporção de 1:1:1. As plantas permaneceram sob sombrite $50 \%$ entre fevereiro e abril de 2003, quando foram transferidas para casade-vegetação. Durante o período em que as plantas permaneceram na casa-de-vegetação, foi aplicado uma solução nutritiva composta por $\mathrm{KH}_{2} \mathrm{PO}_{4}$ e uréia, na dosagem de $10 \mathrm{~mL}^{\text {planta-1}}{ }^{-1}$. As aplicações foram

Rev. Bras. PI. Med., Botucatu, v.12, n.3, p.243-249, 2010. 
feitas semanalmente, durante seis semanas, a partir de setembro de 2003. Em novembro de 2003 as plantas foram transplantadas para canteiros de alvenaria em área de telado. Os canteiros foram previamente adubados com esterco bovino, adubo 1020-20 e nitrocálcio, de acordo com resultado de análise de solo.

Os caracteres morfológicos e fisiológicos avaliados nas progênies foram dias da semeadura à emergência; altura de planta, em $\mathrm{cm}$, avaliada aos 90, 180, 270 e 360 dias após a semeadura; diâmetro à base do caule, em $\mathrm{mm}$, avaliado com auxílio de um paquímetro digital, aos 90, 180, 270 e 360 dias após a semeadura; número de folhas por planta, avaliado aos 90 e 180 dias após a semeadura; taxa de crescimento em altura, em cm dia ${ }^{-1}$, avaliada a partir da diferença entre a altura aos 360 dias e aos 90 dias, dividido por 270 dias; taxa de crescimento em diâmetro à base do caule, em $\mathrm{mm} \mathrm{dia}^{-1}$, avaliada a partir da diferença entre o diâmetro aos 360 dias e aos 90 dias, dividido por 270 dias; comprimento e largura de folha, em $\mathrm{cm}$ e número de espinhos por folha.

Os dados referentes aos caracteres de morfologia foliar foram baseados na média de três folhas, retiradas da parte inferior, mediana e superior de cada planta. Para atender as pressuposições da ANOVA os dados das variáveis altura e diâmetro à base do caule aos 360 dias e taxa de crescimento em altura foram transformados para raiz quadrada, altura aos 90 dias para raiz quadrada da altura ${ }^{3}$ (altura elevada na terceira potência) e, dias da semeadura à emergência, para o logaritmo de base 10 dos dados originais (log10). Todas estas transformações de dados foram feitas por indicação do próprio programa SAS (SAS Institute, 2000).

O delineamento experimental foi em blocos casualizados, com quatro repetições e cinco plantas por parcela. Os dados foram submetidos à análise de variância para cada um dos caracteres e à análise

TABELA 1. Origem dos acessos do banco ativo de germoplasma de espinheira-santa (M. ilicifolia e M. aquifolium).

\begin{tabular}{clccl}
\hline População & \multicolumn{1}{c}{ Acesso } & Total & Origem & \multicolumn{1}{c}{ Município } \\
\hline 1 & $1-7$ & 7 & PR $^{(2)}$ & Encruzilhada do Sul \\
2 & $8-16$ & 9 & PR & Encruzilhada do Sul \\
3 & 18 & 1 & PR & Piratini \\
4 & $19,20,24,25,28,30,31,33-39,41$ & 15 & PR & Piratini \\
6 & $44-46,48-54$ & 10 & PR & Piratini \\
7 & 55,$56 ; 86,87$ & 4 & PR & Arroio Grande \\
8 & 57 & 1 & PR & Arroio Grande \\
11 & 60 e 92 & 2 & PR & Arroio Grande \\
12 & 61 & 1 & PR & Arroio Grande \\
13 & $62-64,66-69,71-75$ & 12 & PR & Candiota \\
14 & $76-83$ & 8 & PR & Candiota \\
15 & 84 & 1 & PR & Hulha Negra \\
16 & 85 & 1 & Q ${ }^{(3)}$ & Pelotas \\
17 & $88-89$ & 2 & PR & Arroio Grande \\
18 & $90^{(1)}$ & 1 & PR & Farroupilha \\
19 & $91^{(1)}$ & 1 & Q & Farroupilha \\
20 & $93-94$ & 2 & PR & Arroio Grande \\
21 & 95 & 1 & Q & Cachoeirinha \\
23 & 101 & 1 & Q & Caxias do Sul \\
24 & 102 & 1 & Q & Vacaria \\
25 & 103,$104 ; 106,107,110^{(1)}, 111$ & 6 & PR & Esmeralda \\
26 & 105 & 1 & PR & Vacaria \\
28 & $113^{(1)}$ & 1 & Q & São Marcos \\
\hline Total geral & & & \\
\hline
\end{tabular}

(1)Acessos pertencentes à espécie M. aquifolium; (2)Propriedade rural (coletados no campo); (3)Quintal 
de variância multivariada através do programa estatístico SAS, versão 8.2 (SAS Institute, 2000). Através deste programa, foram obtidas a matriz de variâncias e covariâncias residuais e as médias dos acessos.

Foram então estimadas, com auxílio do programa GENES (Cruz, 2001), as variáveis canônicas. Esta análise possibilita visualizar a similaridade entre indivíduos em gráficos de dispersão bi ou tridimensionais, além de verificar a importância relativa dos caracteres no estudo da diversidade (Cruz $\&$ Regazzi, 2001). Esta técnica tem a vantagem de manter o princípio do processo de agrupamento com base na distância de Mahalanobis ( $\left.D^{2}\right)$, que leva em consideração as correlações residuais existentes entre caracteres.

Para este trabalho, devido ao reduzido número de indivíduos (matrizes) - que deram origem às progênies - nas populações, os acessos do banco ativo de germoplasma de espinheira-santa foram considerados como pertencentes a uma metapopulação, em que interessava saber a divergência entre osacessos, representados por famílias de irmãos maternos. Assim, não foram feitas análises de divergência entre populações.

\section{RESULTADO E DISCUSSÃO}

O trabalho finalizou aos 360 dias, pois as avaliações realizadas se referem apenas à fase de produção das mudas.

Foi evidenciada significância a $1 \%$ de probabilidade de erro, pelo teste $\mathrm{F}$, para todos os caracteres na análise de variância (Tabela 2). Os coeficientes de variação foram baixos para a maioria dos caracteres, sendo considerados médios para altura aos 90, 180 e 270 dias, número de folhas por planta aos 90 e 180 dias e crescimento em diâmetro à base do caule, o que mostra a boa precisão do experimento.

Foi observado incremento médio em altura ao longo das avaliações, de $2,9 \mathrm{~cm}$ entre 90 e 180 dias, $9,09 \mathrm{~cm}$ entre 180 e 270 dias e $10,29 \mathrm{~cm}$ entre 270 e 360 dias após a semeadura, o que corrobora os resultados obtidos por Magalhães et al. (1992) em trabalho desenvolvido com $M$. ilicifolia. Os autores observaram que até o sétimo mês as plantas apresentaram taxa baixa de crescimento, tendo ocorrido maior incremento a partir do oitavo mês. Eles sugerem que, além dos fatores inerentes à fisiologia da espécie, o aumento no fotoperíodo tenha influenciado na indução do crescimento vegetativo.

TABELA2. Resumo da análise da variância para 16 caracteres morfo-fisiológicos em progênies de espinheirasanta.

\begin{tabular}{|c|c|c|c|c|}
\hline Caráter & Amplitude & Média & $Q M G^{(10)}$ & $\begin{array}{c}\mathbf{C V}^{(11)} \\
(\%)\end{array}$ \\
\hline $\mathrm{DE}^{(1)}$ & $23,14-66,53$ & 40,11 & $0,03^{* *}$ & 4,03 \\
\hline $\mathrm{A} 1^{(2)}(\mathrm{cm})$ & $1,17-4,83$ & 2,91 & $9,10^{* *}$ & 17,83 \\
\hline $\mathrm{A} 2^{(2)}(\mathrm{cm})$ & $2,06-9,78$ & 5,81 & $7,19^{* *}$ & 13,08 \\
\hline$A 3^{(2)}(\mathrm{cm})$ & $5,02-24,95$ & 14,90 & $40,17^{\star *}$ & 14,32 \\
\hline $\mathrm{A} 4^{(2)}(\mathrm{cm})$ & $10,45-51,63$ & 25,19 & $1,66^{* *}$ & 7,28 \\
\hline $\mathrm{D} 1^{(3)}(\mathrm{mm})$ & $0,45-0,92$ & 0,68 & $0,04^{* *}$ & 4,90 \\
\hline $\mathrm{D} 2^{(3)}(\mathrm{mm})$ & $0,73-1,61$ & 1,22 & $0,14^{* *}$ & 9,34 \\
\hline $\mathrm{D}^{(3)}(\mathrm{mm})$ & $1,16-3,60$ & 2,48 & $0,60^{* *}$ & 10,32 \\
\hline $\mathrm{D} 4^{(3)}(\mathrm{mm})$ & $2,43-8,06$ & 5,07 & $0,17^{* *}$ & 6,96 \\
\hline $\mathrm{F} 1^{(4)}$ & $1,58-5,69$ & 4,01 & $2,15^{\star *}$ & 14,81 \\
\hline$F 2^{(4)}$ & $4,41-12,02$ & 7,68 & $5,93^{* *}$ & 11,32 \\
\hline $\mathrm{C}_{\mathrm{A}}{ }^{(5)}\left(\mathrm{cm} \mathrm{dia} \mathrm{C}^{-1}\right)$ & $0,38-1,79 \times 10^{-1}$ & $0,82 \times 10^{-1}$ & $0,64 \times 10^{-3 * *}$ & 8,11 \\
\hline$C_{D}{ }^{(6)}\left(m m d i a^{-1}\right)$ & $0,73-2,64 \times 10^{-2}$ & $1,60 \times 10^{-2}$ & $0,43 \times 10^{-5 * *}$ & 15,74 \\
\hline $\mathrm{CF}^{(7)}(\mathrm{cm})$ & $4,86-11,75$ & 5,88 & $4,62^{\star \star}$ & 6,56 \\
\hline $\mathrm{LF}^{(8)}(\mathrm{cm})$ & $1,96-3,82$ & 2,47 & 0,29 ** & 6,76 \\
\hline $\mathrm{NE}^{(9)}$ & $10,80-28,04$ & 14,78 & $27,78^{\star *}$ & 6,64 \\
\hline \multicolumn{5}{|c|}{$G L_{\text {Residuo }}$ para todos os caracteres: 219} \\
\hline
\end{tabular}

(1)DE - dias da semeadura à emergência; (2) A1, A2, A3, A4 - altura de planta, respectivamente, aos 90, 180, 270 e 360 dias; (3)D1, D2, D3, D4 - diâmetro à base do caule, respectivamente, aos 90, 180, 270 e 360 dias; (4)F1, F2 - número de folhas por planta, respectivamente, aos 90 e 180 dias; ${ }^{(5)} \mathrm{C}_{\mathrm{A}}$ - crescimento em altura; ${ }^{\left({ }^{6}\right)} \mathrm{C}_{\mathrm{D}}$ - crescimento em diâmetro à base do caule; ${ }^{(7)} \mathrm{CF}$ - comprimento de folha; ${ }^{(8)} \mathrm{LF}-$ largura de folha; ${ }^{(9)} \mathrm{NE}$ - número de espinhos por folha; ${ }^{(10)}$ quadrado médio do genótipo; ${ }^{(11)}$ coeficiente de variação.

${ }^{*}$ Significativo a $1 \%$ de probabilidade de erro pelo teste $\mathrm{F}$. 
Este fator também pode ter influenciado nos resultados observados neste trabalho, pois o crescimento em altura começou a ter maior incremento após os 180 dias, que corresponde ao mês de setembro, quando o fotoperíodo está em ascendência. Em plantas de $M$. ilicifolia com idade maior do que as avaliadas neste trabalho, Radomski \& Scheffer (2004) observaram aumento médio em altura de $31,8 \mathrm{~cm}$, entre 23 e 75 meses.

Assim como a altura, foi observado aumento no diâmetro à base do caule ao longo das avaliações, de $0,54 \mathrm{~mm}$ entre 90 e 180 dias, $1,26 \mathrm{~mm}$ entre 180 e 270 dias e de $2,59 \mathrm{~mm}$ entre 270 e 360 dias após a semeadura (Tabela 2). Variação de 0,6 a 2,6 $\mathrm{mm}$ para este caráter foi observada por Scheffer (2001) em plantas de M. ilicifolia cultivadas em tubetes, aos 11 meses de idade. Para esta mesma espécie, Nicoloso et al. (2000) identificaram diâmetro médio de 0,75 $\mathrm{mm}$ aos 135 dias após a semeadura, em plantas cultivadas em sacos de polietileno.

Houve aumento de 3,67 folhas por planta entre 90 e 180 dias após a semeadura (Tabela 2). $\mathrm{O}$ aumento evidenciado para este caráter acompanhou o crescimento em altura entre 90 e 180 dias, o que também foi observado por Magalhães et al. (1992) em trabalho desenvolvido com $M$. ilicifolia. Os autores observaram maior incremento para este caráter a partir do oitavo mês e aos seis meses identificaram média de 9,5 folhas por planta, valor maior do que o identificado neste trabalho para o mesmo período (180 dias).

Através da análise de variáveis canônicas, foi observado que as três primeiras variáveis responderam por $70,66 \%$ da variação total (Tabela $3)$. Através dos escores das três primeiras variáveis canônicas foi elaborado gráfico de dispersão tridimensional que mostra a formação de três grupos para os acessos de espinheira-santa (Figura 1). Os acessos 90, de Farroupilha, e 76, de Candiota, pertencentes respectivamente às espécies $M$. aquifolium e M. ilicifolia, foram agrupados juntos; o acesso 1, de Encruzilhada do Sul, ficou em grupo isolado e os demais acessos foram inseridos em um grupo maior. Os acessos 90 e 76 apresentaram médias semelhantes para os caracteres que mais contribuíram para a divergência genética entre os acessos de espinheira-santa, com base nos autovetores, na análise de variáveis canônicas (Tabela 3), o que explica este agrupamento. Através de análise multivariada em caracteres morfológicos avaliados nas matrizes que deram origem a estas progênies, Mariot et al. (2008) também observaram o agrupamento de acessos de $M$. ilicifolia e $M$. aquifolium. Além disso, as duas espécies de Maytenus compartilham alelos, pois ocorre fluxo gênico entre elas (Perecin \& Kageyama, 2002), o que reforça a explicação para o agrupamento destes acessos.

Os caracteres que mais contribuíram para a divergência genética, com base nos autovetores, foram altura de planta aos 360 dias, seguido de diâmetro à base do caule aos 360 dias e número de folhas por planta aos 180 dias (Tabela 3). A grande diferença entre os acessos da Região Nordeste do Estado em relação aos demais para altura de planta e diâmetro à base do caule aos 360 dias (Tabela 4), explica a maior importância destes caracteres para a divergência genética. Os caracteres relacionados ao crescimento são, portanto, importantes para a diferenciação dos acessos de espinheira-santa com base na análise de progênies, além de serem importantes para seleção em programas de melhoramento genético, pois a espinheira-santa é considerada espécie de crescimento lento (Magalhães et al., 1992; Rachwal et al., 1997; Nicoloso et al., 2000).

TABELA 3. Estimativas dos autovalores $\left(\lambda_{j}\right)$ associados às variáveis canônicas e respectivos coeficientes de ponderação (autovetores) de 16 caracteres morfo-fisiológicos em progênies de espinheira-santa.

\begin{tabular}{|c|c|c|c|c|c|c|c|c|c|c|c|c|c|c|c|c|c|}
\hline \multirow{2}{*}{$\lambda_{j}$} & \multirow{2}{*}{$\begin{array}{l}\lambda_{j}(\%) \\
\text { acumulada }\end{array}$} & \multicolumn{16}{|c|}{ Caracteres/Autovetores } \\
\hline & & $\mathrm{DE}^{1}$ & $A 1^{2}$ & $A 2^{2}$ & $A 3^{2}$ & $A 4^{2}$ & $\mathrm{D} 1^{3}$ & $\mathrm{D} 2^{3}$ & D3 $^{3}$ & D4 ${ }^{3}$ & $F 1^{4}$ & $F 2^{4}$ & $\mathrm{C}_{\mathrm{A}}{ }^{5}$ & $C_{D}{ }^{6}$ & $\mathrm{CF}^{7}$ & $\mathrm{CF}^{8}$ & $\mathrm{NE}^{9}$ \\
\hline 0,0606 & 40,65 & $-0,30$ & 3,46 & 0,14 & 0,05 & $-42,48$ & $-0,34$ & $-0,03$ & $-0,34$ & 4,00 & $-0,76$ & 0,91 & 41,1 & $-3,96$ & $-0,12$ & 0,03 & 0,14 \\
\hline 0,0347 & 63,94 & $-0,19$ & 0,53 & $-0,13$ & 0,07 & $-2,30$ & 1,63 & 0,08 & 0,58 & $-15,52$ & $-0,59$ & 0,35 & 1,99 & 14,59 & $-0,10$ & 0,25 & $-0,15$ \\
\hline 0,0100 & 70,66 & $-0,34$ & 0,55 & $-2,01$ & 0,29 & 2,40 & $-0,06$ & 0,66 & $-0,80$ & 0,49 & $-1,75$ & 2,52 & $-2,41$ & $-0,38$ & 0,29 & $-0,19$ & 0,35 \\
\hline 0,0060 & 74,69 & $-0,91$ & 0,77 & $-1,52$ & 1,71 & $-1,31$ & $-0,49$ & 0,07 & $-0,43$ & 0,23 & $-0,64$ & 0,19 & 1,26 & 0,22 & 0,35 & 0,38 & $-0,46$ \\
\hline 0,0045 & 77,76 & $-0,58$ & 0,25 & 0,86 & $-0,82$ & $-1,28$ & $-0,19$ & $-1,66$ & 1,99 & 1,78 & $-1,15$ & 0,89 & 0,79 & $-1,86$ & 0,67 & $-0,53$ & $-0,60$ \\
\hline 0,0040 & 80,45 & $-0,72$ & 0,74 & $-1,99$ & $-0,13$ & $-0,42$ & 0,01 & 0,14 & 1,39 & 1,37 & $-0,02$ & $-0,28$ & 0,47 & $-2,05$ & 0,09 & $-0,17$ & 0,19 \\
\hline 0,0035 & 82,84 & $-0,60$ & 0,49 & 0,36 & $-0,45$ & 0,17 & $-0,11$ & $-0,89$ & 0,23 & 0,77 & $-0,64$ & $-0,11$ & $-0,07$ & $-0,42$ & $-0,29$ & $-0,34$ & 1,22 \\
\hline 0,0033 & 85,12 & $-0,08$ & 0,49 & 0,62 & $-1,14$ & $-0,84$ & $-0,45$ & 0,51 & 0,09 & 0,03 & $-0,63$ & 0,01 & 0,49 & 0,65 & 0,45 & $-0,08$ & $-0,43$ \\
\hline 0,0032 & 87,27 & 0,26 & $-0,13$ & 0,38 & $-0,89$ & 0,58 & $-0,40$ & 0,91 & 0,19 & $-0,06$ & 0,74 & $-0,24$ & $-0,21$ & 0,22 & $-0,89$ & 0,13 & 0,70 \\
\hline 0,0030 & 89,31 & 0,62 & 0,03 & $-0,74$ & 0,32 & $-0,17$ & 0,36 & 0,30 & 0,64 & 0,72 & $-0,58$ & 0,13 & 0,15 & $-0,63$ & $-0,26$ & 0,54 & $-0,07$ \\
\hline 0,0030 & 91,32 & 0,07 & $-0,76$ & 0,29 & 0,52 & $-1,55$ & 0,09 & $-0,13$ & $-0,46$ & $-0,41$ & 0,81 & $-0,21$ & 0,76 & 0,89 & 1,25 & $-0,09$ & $-0,44$ \\
\hline 0,0029 & 93,25 & 0,13 & 0,28 & 0,06 & 0,89 & $-0,81$ & 0,48 & $-0,17$ & 0,37 & $-0,44$ & $-0,53$ & 0,38 & $-0,14$ & $-0,10$ & $-0,23$ & 0,59 & $-0,03$ \\
\hline 0,0028 & 95,13 & 0,26 & 0,65 & $-0,13$ & $-0,67$ & 0,46 & 0,09 & $-0,40$ & $-0,51$ & $-0,43$ & 0,80 & 0,24 & $-0,47$ & 1,07 & $-0,50$ & 0,49 & $-0,02$ \\
\hline 0,0027 & 96,93 & 0,35 & 0,95 & $-0,41$ & $-0,68$ & $-1,18$ & 0,39 & 0,54 & $-0,53$ & 0,12 & $-0,03$ & 0,11 & 1,87 & $-0,04$ & 1,06 & $-0,85$ & $-0,72$ \\
\hline 0,0024 & 98,57 & $-0,26$ & $-0,90$ & 1,21 & $-0,89$ & 0,71 & 1,44 & 0,06 & $-0,15$ & $-2,18$ & $-0,51$ & $-0,22$ & $-0,15$ & 2,39 & $-0,54$ & $-0,02$ & $-0,27$ \\
\hline 0,0021 & 100,0 & $-0,40$ & $-0,01$ & 1,25 & $-1,44$ & $-5,82$ & $-0,49$ & $-0,10$ & 0,17 & $-0,11$ & $-0,17$ & 0,49 & 6,60 & $-0,34$ & 0,82 & 0,38 & $-0,76$ \\
\hline
\end{tabular}

${ }^{1} \mathrm{DE}$ - dias da semeadura à emergência; ${ }^{2} \mathrm{~A} 1, \mathrm{~A} 2, \mathrm{~A} 3, \mathrm{~A} 4$ - altura de planta, respectivamente, aos 90, 180, 270 e 360 dias; ${ }^{3} \mathrm{D} 1, \mathrm{D} 2, \mathrm{D} 3$, D4 - diâmetro à base do caule, respectivamente, aos $90,180,270$ e 360 dias; ${ }^{4} \mathrm{~F} 1, \mathrm{~F} 2$ - número de folhas por planta, respectivamente, aos 90 e 180 dias; ${ }^{5} \mathrm{C}_{\mathrm{A}}$ - crescimento em altura; ${ }^{6} \mathrm{C}_{\mathrm{D}}$ - crescimento em diâmetro à base do caule; ${ }^{7} \mathrm{CF}$ - comprimento de folha; ${ }^{8} \mathrm{LF}-$ largura de folha; ${ }^{9} \mathrm{NE}$ - número de espinhos por folha. 
TABELA 4. Média dos caracteres altura de planta e diâmetro à base do caule aos 360 dias nas progênies de espinheira-santa do Banco Ativo de Germoplasma da Embrapa Clima Temperado/Universidade Federal de Pelotas.

\begin{tabular}{clccc}
\hline População & \multicolumn{1}{c}{ Acessos } & Região & A4 $^{(2)}(\mathbf{c m})$ & $\mathbf{D 4}^{(3)}(\mathbf{m m})$ \\
\hline 1 & $1-7$ & Sul & 21,65 & 4,53 \\
2 & $8-16$ & Sul & 24,34 & 5,65 \\
3 & 18 & Sul & 17,25 & 3,84 \\
4 & $19,20,24,25,28,30,31,33-39,41$ & Sul & 19,64 & 4,94 \\
6 & $44-46,48-54$ & Sul & 20,00 & 4,81 \\
7 & 55,$56 ; 86,87$ & Sul & 23,01 & 5,27 \\
8 & 57 & Sul & 23,99 & 4,15 \\
11 & 60 e 92 & Sul & 28,20 & 4,61 \\
12 & 61 & Sul & 23,31 & 4,89 \\
13 & $62-64,66-69,71-75$ & Sul & 26,14 & 4,94 \\
14 & $76-83$ & Sul & 27,74 & 4,26 \\
15 & 84 & Sul & 25,03 & 5,96 \\
16 & 85 & Sul & 14,67 & 2,95 \\
17 & $88-89$ & Sul & 27,33 & 5,71 \\
18 & $90^{(1)}$ & Nordeste & 37,25 & 4,66 \\
19 & $91^{(1)}$ & Nordeste & 30,88 & 5,44 \\
20 & $93-94$ & Sul & 25,15 & 4,57 \\
21 & 95 & Metropolitana & 35,63 & 6,17 \\
23 & 101 & Nordeste & 46,64 & 6,04 \\
24 & 102 & Nordeste & 10,32 & 2,45 \\
25 & 103,$104 ; 106,107,110^{(1)}, 111$ & Nordeste & 41,20 & 7,01 \\
26 & 105 & Nordeste & 42,60 & 6,11 \\
28 & $113^{(1)}$ & Nordeste & 29,40 & 5,55 \\
\hline
\end{tabular}

(1)Acessos pertencentes à espécie M. aquifolium; A4(2) - altura de planta aos 360 dias; D4(3) - diâmetro à base do caule aos 360 dias.

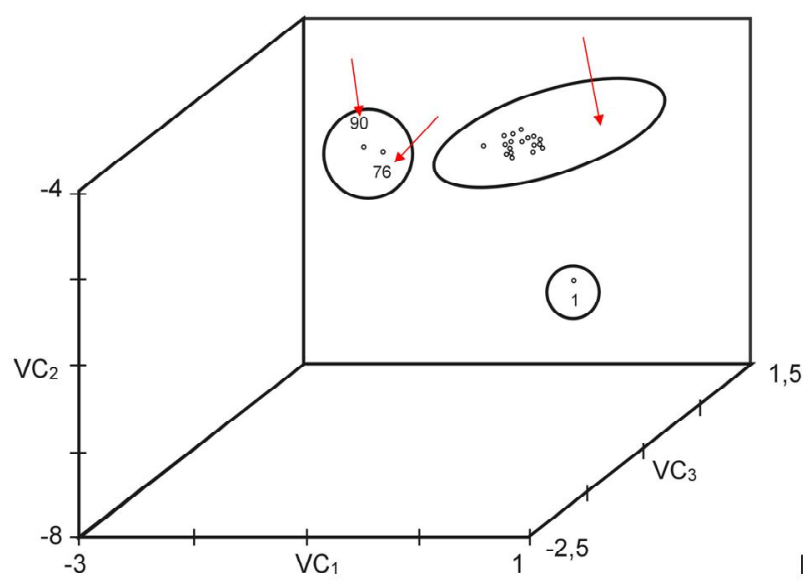

Acesso 1 - M. ilicifolia; Acesso 76 - M. ilicifolia; Acesso 90 M. aquifolium

FIGURA 1. Gráfico de dispersão dos acessos de espinheira-santa em relação às três primeiras variáveis canônicas $\left(\mathrm{VC}_{1}, \mathrm{VC}_{2}\right.$ e $\left.\mathrm{VC}_{3}\right)$, com base em 16 caracteres morfo-fisiológicos avaliados nas progênies.

Os caracteres de menor importância são aqueles cujos coeficientes de ponderação (autovetores) são de maior magnitude, em valor absoluto, nas últimas variáveis canônicas (Cruz \&
Regazzi, 2001), o que corresponde ao crescimento em altura $\left(C_{A}\right)$ e crescimento em diâmetro à base do caule $\left(C_{D}\right)$ (Tabela 3$)$. Em trabalho desenvolvido com cupuaçuzeiro, visando seleção de descritores para caracterização de germoplasma, Alves et al. (2003) observaram que a eliminação de variáveis de menor importância identificadas na análise de componentes principais não ocasionou perda significativa de informação da variabilidade genética. Da mesma forma, este trabalho permite a indicação de descritores importantes para caracterização de germoplasma de espinheira-santa, como altura e diâmetro à base do caule aos 360 dias e número de folhas por planta aos 180 dias - caracteres de maior importância para a divergência genética.

As análises multivariadas foram eficientes para a separação dos acessos de espinheira-santa com base em caracteres morfológicos e fisiológicos avaliados nas progênies. A separação dos acessos em apenas três grupos, entretanto, revela que, para os caracteres avaliados nas progênies, não foi detectada grande variabilidade genética.

As análises multivariadas são ferramentas importantes para caracterizar germoplasma, pois permitem descrever e agrupar um conjunto de acessos, levando em consideração simultaneamente várias características e a relação existente entre elas (Rojas, 2003). Neste sentido, os trabalhos envolvendo 
a caracterização morfológica e fisiológica em espinheira-santa serão mais eficientes dentro do banco ativo de germoplasma.

Estes resultados têm aplicação prática, pois permitem selecionar os caracteres mais importantes para caracterização dos acessos, o que facilita os trabalhos no banco de germoplasma. Além disso, com relação ao uso, o conhecimento prévio dos caracteres avaliados nos acessos contribui para a escolha de genótipos para programas de melhoramento da espécie.

\section{CONCLUSÃO}

- Os caracteres morfo-fisiológicos utilizados na análise multivariada, avaliados na fase de produção de mudas, permitiram a separação dos acessos de espinheira-santa.

- Não foi identificada alta variabilidade genética para os caracteres avaliados na fase de mudas.

- Foi possível identificar caracteres mais importantes para caracterização morfo-fisiológica de germoplasma de espinheira-santa na fase de muda.

\section{REFERÊNCIA}

ALVES, R.M. et al. Seleção de descritores botânicoagronômicos para caracterização de germoplasma de cupuaçuzeiro. Pesquisa Agropecuária Brasileira, v.38, n.7, p.807-18, 2003.

BITTENCOURT, J.V.M. Variabilidade genética em populações naturais de Maytenus ilicifolia por meio de marcadores RAPD. 2000. 58p. Dissertação (Mestrado em Agronomia) - Faculdade de Agronomia, Universidade Federal do Paraná, Curitiba.

CARVALHO-OKANO, R.M. Estudos taxonômicos do gênero Maytenus Mol. emend. Mol. (CELASTRACEAE) do Brasil extra-amazônico. 1992. 253p. Tese (Doutorado em Ciências) - Curso de Pós-Graduação em Biologia Vegetal, Universidade Estadual de Campinas, Campinas.

CARVALHO-OKANO, R.M.; LEITÃO FILHO, H.F. O gênero Maytenus Mol. emend. Mol. (Celastraceae) no Brasil extra-amazônico. In: REIS, M.S.; SILVA, S.R. Conservação e uso sustentável de plantas medicinais e aromáticas: Maytenus spp., espinheira-santa. Brasília: IBAMA, 2004. p.11-52.

CRUZ, C.D. Programa Genes: aplicativo computacional em genética e estatística. Viçosa: Editora da Universidade Federal de Viçosa, 2001. 648p.

CRUZ, C.D.; REGAZZI, A.J. Modelos biométricos aplicados ao melhoramento genético. 2.ed. Viçosa: Editora da Universidade Federal de Viçosa, 2001. 390p. DI STASI, L.C. Aspectos químicos e farmacológicos da espinheira-santa: uma análise da utilidade dos dados. In:REIS, M.S.; SILVA, S.R. Conservação e uso sustentável de plantas medicinais e aromáticas: Maytenus spp., espinheira-santa. Brasília: IBAMA, 2004. p.67-92.

MAGALHÃES, P.M. et al. Conservação da espécie
Maytenus ilicifolia Mart. ex Reiss. (espinheira-santa) através da técnica de propagação de sementes. Revista do Instituto Florestal, v.4, p.519-22, 1992.

MARIOT, M.P. Recursos genéticos de espinheira-santa (Maytenus ilicifolia e M. aquifolium) no Rio Grande do Sul. 2005. 131p. Tese (Doutorado em Agronomia) Faculdade de Agronomia "Eliseu Maciel", Universidade Federal de Pelotas, Pelotas.

MARIOT, M.P. et al. Variabilidade em matrizes de acessos de espinheira-santa. Ciência Rural, v.38, n.2, p.351-7, 2008.

MOSSI, A.J. Variabilidade genética e de compostos voláteis e semi-voláteis em Maytenus ilicifolia Mart. ex Reiss. 2003. 101p. Tese (Doutorado em Ciências) Curso de Pós-graduação em Ecologia e Recursos Naturais, Centro de Ciências Biológicas e da Saúde, Universidade Federal de São Carlos, São Carlos.

NICOLOSO, F.T. et al. Recipientes e substratos na produção de mudas de Maytenus ilicifolia e Apuleia leocarpa. Ciência Rural, v.30, n.6, p.987-92, 2000.

PERECIN, M.B.; KAGEYAMA, P.Y. Variabilidade isoenzimática em populações naturais de espinheirasanta Maytenus aquifolia Mart. e M. ilicifolia Mart. ex Reiss. e suas implicações para o manejo da conservação. Revista Brasileira de Plantas Medicinais, v.4, n.2, p.80-90, 2002.

PERECIN, M.B.; STEENBOCK, W.; REIS, M.S. Genética de populações de espinheira-santa. In: REIS, M.S.; SILVA, S.R. Conservação e uso sustentável de plantas medicinais e aromáticas: Maytenus spp., espinheirasanta. Brasília: IBAMA, 2004. p.115-44.

RACHWAL, M.F.G.; CURCIO, G.R.; MEDRADO, M.J.S. Desenvolvimento e produção de massa foliar de espinheira-santa (Maytenus ilicifolia) a pleno sol, em cambissolo húmico no município de Colombo-PR. Boletim de Pesquisa Florestal, n.35, p.91-3, 1997.

RADOMSKI, M.I.; SCHEFFER, M.C. Características fenotípicas de $\mathbf{4 4}$ progênies de Maytenus ilicifolia Mart. cultivadas no município de Ponta Grossa, PR. Colombo: Embrapa Florestas, 2004. 6p. (Embrapa Florestas. Circular técnica, 86).

ROJAS, W. Análisis multivariado em estudios de variabilidad genética. In: FRANCO, T.; HIDALGO, R. (Eds.). Análisis estadístico del datos de caracterización morfológica de recursos fitogenéticos. Roma: IPGRI, 2003. p.85-9. (IPGRI. Boletin tecnico, 8).

SAS INSTITUTE. SAS/STAT user's guide. Cary: Statistical Analysis System Institute, 2000. CD-ROM.

SCHEFFER, M.C. Sistema de cruzamento e variação genética entre populações e progênies de espinheirasanta. 2001. 104p. Tese (Doutorado em Engenharia Florestal) - Faculdade de Agronomia, Universidade Federal do Paraná, Curitiba.

STEENBOCK, W. Fundamentos para o manejo de populações naturais de espinheira-santa, Maytenus ilicifolia Mart. ex Reiss. (Celastraceae). 2003. 145p. Dissertação (Mestrado em Recursos Genéticos Vegetais) - Faculdade de Agronomia, Universidade Federal de Santa Catarina, Florianópolis.

VIEIRA, R.F. Conservation of medicinal and aromatic plants in Brazil. In: JANICK, J. (Ed.). Perspectives on new crops and new uses. Alexandria, VA: ASHS Press, 1999. p.152-9. 